\title{
COVID-19: the risk of respiratory techniques in healthcare workers
}

\author{
Rodrigo Torres-Castro ${ }^{1} \cdot$ Jordi Vilaró $^{2} \cdot$ Roberto Vera-Uribe $^{1}$
}

Received: 7 April 2020 / Revised: 8 April 2020 / Accepted: 9 April 2020 / Published online: 21 April 2020

(c) International Spinal Cord Society 2020

\section{To the Editor:}

In December 2019, Wuhan, China, was identified as having a cluster of pneumonia cases of unknown etiology. Subsequent investigations revealed a novel coronavirus, COVID-19, as the cause of the most significant pandemics of the modern era [1]. As the pandemic progresses, it is regrettable to know that healthcare workers are being infected constantly.

COVID-19 is spread primarily by respiratory droplets contaminating surfaces and hands, transmitting the virus to another person [1], including healthcare workers, who have a high risk of contracting this infection, particularly when applying respiratory procedures. The first reports from Wuhan found 40 healthcare workers among the first consecutive 138 patients hospitalized [2].

Spinal cord injury (SCI) is characterized by significant respiratory compromise secondary to motor loss that requires respiratory support in the acute and chronic stages, especially in people with cervical SCI. The most common respiratory interventions that healthcare workers have used are non-invasive ventilation (NIV), to support the inspiratory muscles, and mechanical cough assist, to support cough weakness, extubation, and decannulation [3].

Healthcare workers must pay attention to the high-risk interventions that may expose them to contamination due to the dispersion of droplets when attending patients with COVID-19. Several respiratory techniques are used in acute patients, such as aerosol nebulization, mucous clearance, NIV, bronchoscopy, tracheal intubation, manual ventilation before intubation, tracheotomy, endotracheal aspiration, cardiopulmonary resuscitation and extubation [4].

Rodrigo Torres-Castro

klgorodrigotorres@gmail.com

1 Department of Physical Therapy, Faculty of Medicine, University of Chile, Santiago, Chile

2 Blanquerna School of Health Sciences, Global Research on Wellbeing (GRoW), Universitat Ramon Llull, Barcelona, Spain
The professionals who work with people with SCI and perform aerosol-generating procedures should take extreme care during and after their interventions. They should wear a waterproof long-sleeved gown, double non-sterile gloves, eye protection (with lateral protection), and a respirator that ensures a level of protection equal to or greater than N95/ FFP2 [5].

Another essential precaution to reduce risk is the use of a mask by the patient. The cough, without wearing a mask, produces an exhaled air jet of $68 \mathrm{~cm}$. This distance is reduced to $30 \mathrm{~cm}$ when wearing a surgical mask. If wearing an $\mathrm{N} 95$ mask, the distance is reduced to $15 \mathrm{~cm}$. In the case of NIV via a full-face mask in a bi-level setting with a single limb circuit, the exhaled air-jet spreads through the mask's holes up to $91.6 \mathrm{~cm}$, depending on the ventilatory parameters that the patients use [5].

Professionals should be aware of the exhalation distance, given the high risk of emitting large amounts of droplets and take the necessary precautions. Maintaining the health and strength of our healthcare workers is critical to avoiding the collapse of our healthcare system and providing the best care for our SCI patients.

Author contributions RTC, JV, RVU conceived the idea, drafted the first version of letter, and approved the final version.

\section{Compliance with ethical standards}

Conflict of interest The authors declare that they have no conflict of interest.

Publisher's note Springer Nature remains neutral with regard to jurisdictional claims in published maps and institutional affiliations.

\section{References}

1. Guan WJ, Ni ZY, Hu Y, Liang WH, Ou CQ, He JX, et al. Clinical Characteristics of Coronavirus Disease 2019 in China. N Engl J Med. 2020. https://doi.org/10.1056/NEJMoa2002032

2. Wang D, Hu B, Hu C, Zhu F, Liu X, Zhang J, et al. Clinical characteristics of 138 hospitalized patients with 2019 novel 
coronavirus-infected pneumonia in Wuhan, China. JAMA. 2020;323:1061-9.

3. Bach JR. Noninvasive respiratory management of high level spinal cord injury. J Spinal Cord Med. 2012;35:72-80.

4. Lazzeri M, Lanza A, Bellini R, Bellofiore A, Cecchetto S, Colombo A, et al. Respiratory physiotherapy in patients with COVID-19 infection in acute setting: a Position Paper of the Italian Association of Respiratory Physiotherapists (ARIR). Monaldi Arch Chest Dis. 2020;90. https://doi.org/10.4081/monaldi.2020.1285

5. Ferioli M, Cisternino C, Leo V, Pisani L, Palange P, Nava S. Protecting healthcare workers from SARS-CoV-2 infection: practical indications. Eur Respir Rev. 2020;29:200068. 